\title{
Balancing a book on the head affects postural control
}

\author{
Eva-Maj Malmström ${ }^{1,2}$, Martin Kronkvist ${ }^{2}$ and Fredrik Tjernström ${ }^{2 *}$ \\ ${ }^{1}$ Department of Neurology and Rehabilitation Medicine, Section for specialized pain Rehabilitation, Clinical Sciences Lund University, Skåne University Hospital, \\ S-221 85 Lund, Sweden \\ ${ }^{2}$ Department of Otorhinolaryngology, Head and Neck Surgery, Clinical Sciences Lund University, Skåne University Hospital, S-221 85 Lund, Sweden
}

\begin{abstract}
An emergent line in postural rehabilitation of dizzy patients is the use of various technical devices, based on creating external feedback postural cues. In this paper we evaluated the effects on postural control of balancing a book on the head, a method available for almost everyone. We tested 12 healthy volunteers ( 7 males, 5 females), aged 20-45 years, with and without balancing a book on the head, standing on a force platform while being posturally perturbed by vibratory simulation to the calfmuscles of the leg. The test conditions balancing a book on the head or not, with eyes open or closed were randomized in order to account for simple order effects.

Balancing a book stabilized postural sway when the eyes were open, predominantly by reducing the anteroposterior sway path and by decreasing the slow compensatory postural adjustments $<0.1 \mathrm{~Hz}(\mathrm{p}=0.002)$.

The stabilizing effect of balancing a book could possibly be attributed to either external sensory information or a diversion of attention from maintaining postural control towards external focus (i.e. balancing a book constitutes a cognitive task). The study shows that a simple task as balancing a book affects postural control and could be used in rehabilitation of patients with postural imbalance.
\end{abstract}

\section{Introduction}

Upright bipedal stance involve both feed-back and feed-forward mechanisms [1]. Feed-back control depends on sensory input (vision, vestibular and proprioceptive) that are processed, integrated and weighted to their relative importance and context in the central nervous system (CNS) [2]. Feed-forward mechanisms depend upon previous postural and sensory experience as well as anticipatory expectance and involve the concept of "internal models", whose output consists of preformed neuromuscular strategies activated in given situations automatically or voluntarily (anticipated movements) [3].

Poor postural control, sometimes expressed as dizziness/imbalance, can most often and to some extent be rehabilitated through exercises. This has been demonstrated both in isolated sensory loss (e.g. unilateral vestibular deafferentation) [4] and in central nervous dysfunction (e.g. multisensory deficits) $[5,6]$. The traditional rehabilitation procedures entail physiotherapeutic exercises best exemplified by individualized vestibular rehabilitation, designed to enhance both other sensory cues and central vestibular compensation mechanisms [7]. Training with technical devices such as Vertiguard ${ }^{\odot}[8]$, and the Wii-Fit ${ }^{\odot}$ balance board [9] has been shown to enhance postural control in a number of different clinical diagnoses. The devices act by creating external feedback cues, thus intensifying the intrinsic feed-back mechanisms, and in the end enhance postural corrections. The devices are commercially available but cost money and thus not available for all. Historically, a common method to correct bad posture was to let subjects balance a book on their head, inducing a more erect and straight posture. In theory, balancing a book on the head could also affect postural control in 2 ways; by diverting attention from standing still or through providing gravitational cues that might affect postural alignment and also postural control.

Postural control can be studied either by examining upright stance with or without postural perturbations. It is generally held that in order to evaluate the dynamics of the system (adaptation, disclose pathology) some sort of perturbation is needed [10]. The ability to adapt to postural disturbances such as vibratory stimulation of the calf muscles can be demonstrated by posturography [11,12]. Vibration applied to a muscle or a muscle tendon increases the firing of the muscle spindles, thus signaling that the muscle is being stretched [13]. The stimulated muscle responds with a reflexive contraction (tonic vibratory reflex) [14]. In healthy subjects, the repeated high-intensity vibration of the calf muscles induces greater body sway that usually decreases over time by adaptation [11].

The aim for the study was to evaluate whether postural control can be affected through the act of balancing a book on the head in healthy controls during vibratory postural perturbations.

\section{Material and methods}

We studied 12 healthy paid volunteers ( 7 male, 5 female) aged 20 45 years (mean $27 \pm 7$ years), weight $60-110 \mathrm{~kg}$ (mean $77.1 \pm 13.6 \mathrm{~kg}$ ), and with body length of $167-190 \mathrm{~cm}$ (mean $1.80 \pm 0.1 \mathrm{~m}$ ). None of the subjects had any experience of similar tests and were naive concerning the study protocol and the methods employed. No one had experienced any otoneurological, neurological, psychiatric, orthopedic or hearing disorder or was using any medication except oral contraceptives.

Correspondenceto: Dr. Fredrik Tjernström, Department of Otorhinolaryngology, Head and Neck Surgery, Clinical Sciences Lund University, Skåne University Hospital, S-221 85 Lund, Sweden; Tel: +4646175849; Fax: +46462110968; E-mail: Fredrik.Tjernstrom@med.lu.se

Key words: postural contro, rehabilitation, external focus, feed-back mechanisms

Received: October 06, 2016; Accepted: November 02, 2016; Published: November 07, 2016 
Alcoholic beverages and sedative drugs were proscribed for 24 hours preceding the testing. Informed written consent was obtained from all the subjects, the experiments were done in accordance with the Helsinki Declaration of 2004, and ethical approval from the local ethical board was obtained.

Test conditions were randomized to account for simple order effects; with and without balancing a book on the head, and with eyes open (EO) and eyes closed (EC). The book measured 215x150x15mm and weighed 340 grams. Test procedure was uniform and the same examiner performed all tests. The subjects were instructed to stand erect but not at attention, with arms crossed over the chest and feet at an angle of about 30 degrees open to the front and with the heals approximately $3 \mathrm{~cm}$ apart on a force platform. For the open eyes condition, the subjects were able to fixate on a mark on the wall 1.5 meters away and at the level of the subject's eyes. In between the tests the subjects were allowed to rest if they so wished. In order to minimize the external disturbances for the test subjects, the recordings were performed while the test subjects listened to the same classical music sequence relayed through headphones.

\section{Method}

Postural control was evaluated by perturbing bipedal stance while standing on a force platform (400x400x75 mm) equipped with six strain-gauge sensors (Figure 1). Forces and torques actuated by the feet were recorded with six degrees of freedom by a custom-built force platform, with accuracy better than $0.5 \mathrm{~N}$. The vibrations were applied to the muscles by two cylindrical vibrators $(0.06 \mathrm{~m}$ long and $0.01 \mathrm{~m}$ in diameters), held in place with an elastic strap around each leg. The vibration amplitude was $1.0 \mathrm{~mm}$ amplitude at a constant frequency of $85 \mathrm{~Hz}$. The vibratory stimulation was executed according to a computer controlled pseudorandom binary sequence (PRBS) schedule [15] for 205 seconds by turning on/off the vibratory stimulation. The vibratory stimulation of 200 s was preceded by a period of 30 s of quiet stance. Each recorded test was divided into quiet stance and 4 perturbation periods (30-80, 80-130, 130-180, and 180-230 seconds, respectively), in order to be able to analyze differences in induced postural sway over time.

The PRBS schedule was composed of stimulation shift periods with random duration between 0.8 - 6.4 seconds (yielding an effective bandwidth of 0.1-2.5 Hz). Thus, the designated PRBS stimuli covered a broad power spectrum and the randomized stimulation reduced

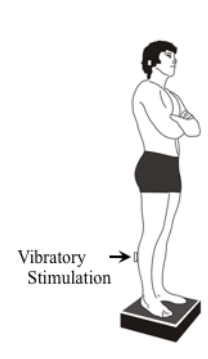

Force Platform

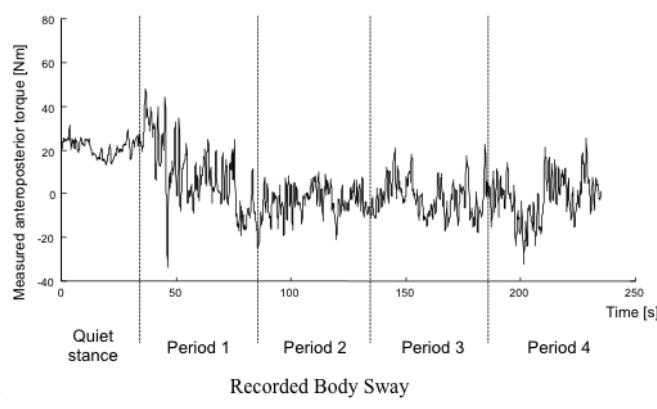

Total sway $\longrightarrow$ High frequency sway

$0.1 \mathrm{~Hz}$ Fast movements $=$ reflexive body corrections Slow movem

Figure 1. Posturography test.

Drawn figure of the posturography procedure. The graph depicts raw data of generated torque during quiets stance and the 4 periods of vibratory stimulation. The generated forces were divided depending on the speed of correctional movements around the frequency of $0.1 \mathrm{~Hz}$, thus distinguishing fast reflexive movements from postural adjustments. the opportunity to make anticipative and pre-emptive adjustments. Each of the perturbation periods contained the same amplitude and duration of perturbing stimulus.

\section{Data analysis}

Torque was measured and the variance of the torque values was analyzed. Postural stability during quiet stance is commonly analyzed using force platforms and the movements of the centre of pressure $(\mathrm{CoP})$, i.e., the point of application of the ground reaction force. Torque correspond to $\mathrm{CoP}$ and torque $\tau$ can be calculated from the formula $\tau=\mathrm{CoP} \cdot \mathrm{Fz}$; where $\mathrm{Fz} \approx \mathrm{m} \cdot \mathrm{g}$; where $\mathrm{m}=$ the assessed subjects mass (in $\mathrm{kg}$ ) and $g=$ gravitational constant $9.81\left(\mathrm{~meter} / \mathrm{s}^{2}\right)$. Hence, changes in recorded torque are equivalent to changes in $\mathrm{CoP}$ [16]. We present torque in the form of energy used towards the support surface to maintain stability [17], which in turn corresponds to the efficiency of standing [18]. Changes in recorded torque from the force platform correspond well to the actual body movements and posture changes induced by vibratory stimulus [19]. The formula for variance is given by;

$$
\begin{aligned}
& \bar{\tau}=\sum_{i=1}^{n} \frac{\tau(i)}{n} \\
& \operatorname{var} \tau=\frac{1}{n-1} \sum_{i=1}^{n}(\tau(i)-\bar{\tau})^{2}
\end{aligned}
$$

$\mathrm{i}=$ sample, $\mathrm{n}=$ number of samples recorded during an analyzed period.

The torque variance values were normalized to account for anthropometric differences between the subjects, using the subject's squared height and squared mass, as height and mass are key factors influencing the body sway recorded by a force platform $[17,20]$. The squared nature of the variance algorithm made it necessary to use normalization with squared parameters to achieve unit agreement.

In the data analysis, the variance of torque was divided into three categories, total, low $(<0.10 \mathrm{~Hz})$, and high frequency $(>0.10 \mathrm{~Hz})$ (Figure 1). A fifth-order digital Finite duration Impulse Response (FIR) filter [21], with filter components selected to avoid aliasing was used for spectral separation. The frequency cut-off level of $0.1 \mathrm{~Hz}$ was based on Fast Fourier Transformation (FFT) analysis of the sway composition under EO and EC conditions [22]. The frequency limit at $0.1 \mathrm{~Hz}$ was also based upon empirical tests on recorded body sway, which have shown that this frequency limit is efficient when separating between fast corrective movements to maintain balance, and the smooth corrective changes in the overall stance [23]. In order to be able to discern the direction of postural sway the analyses were separated into anteroposterior and lateral sway, since vibratory perturbation mainly generate body sway in the anteroposterior plane and thus constitute the major postural response.

\section{Statistics}

The data was analyzed using a repeated measures GLM univariate ANOVA (General Linear Model univariate Analysis of Variance) test on log-transformed values [24]. In the GLM analysis, p-values $<0.05$ were considered statistically significant. With the GLM ANOVA variables, "book on the head", "vision (EO,EC)", and "adaptation (difference between the different periods)", were analyzed with regard to their individual and combined effect on the posturography data. Since the results suggested significant effects from different visual conditions, the study includes a post-hoc analysis in the different visual 
conditions, again by the use of GLM univariate ANOVA.

\section{Results}

None of the subjects dropped their book during the measurements, nor did any patient fall or needed to take a step in order to maintain balance. Vision improved postural stability in the high frequency range $>0.1 \mathrm{~Hz}(\mathrm{p}=0.015)$ during quiet standing (Figure 2 and Table 1). Balancing a book on the head during quiet stance had no significant effect on postural stability in quiet standing (Table 1).

During vibratory perturbation (Table 2 and Figure 3) visual cues (EO) significantly improved postural anteroposterior stability in all frequencies of movements (total $\mathrm{p}<0.001,<0.1 \mathrm{~Hz} \mathrm{p}=0.008,>0.1 \mathrm{~Hz}$ $\mathrm{p}<0.001)$. Vision also reduced lateral sway in total $(\mathrm{p}=0.001)$ and $>0.1 \mathrm{~Hz}$ $(p<0.001)$. Over time or from period to period the induced body sway in anteroposterior direction decreased in all frequencies of movement $(\mathrm{p}<0.001)$, but in lateral sway only in low frequency movements $<0.1 \mathrm{~Hz}$ $(\mathrm{p}=0.023)$. Balancing a book on the head combined with visual cues (EO) significantly improved postural stability in anteroposterior sway $<0.1 \mathrm{~Hz}(\mathrm{p}=0.002)$.

The post-hoc analysis of the different visual conditions (Figure 2) revealed that balancing a book on the head improved postural stability

A

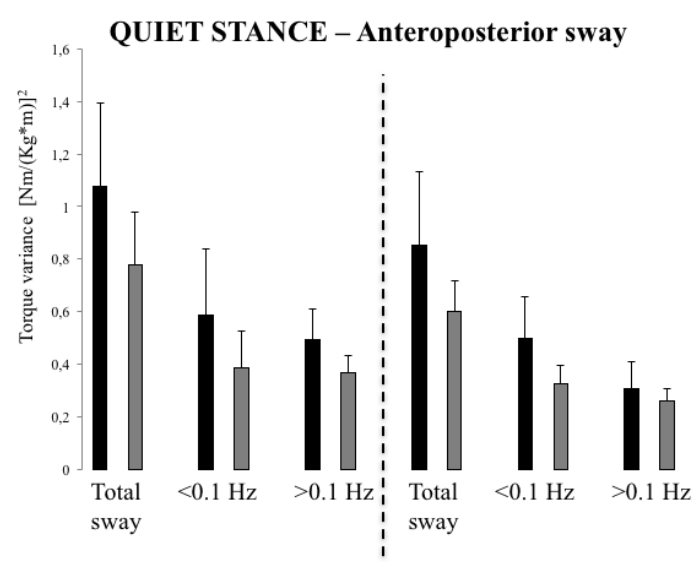

EYES CLOSED $\quad$ EYES OPEN

B

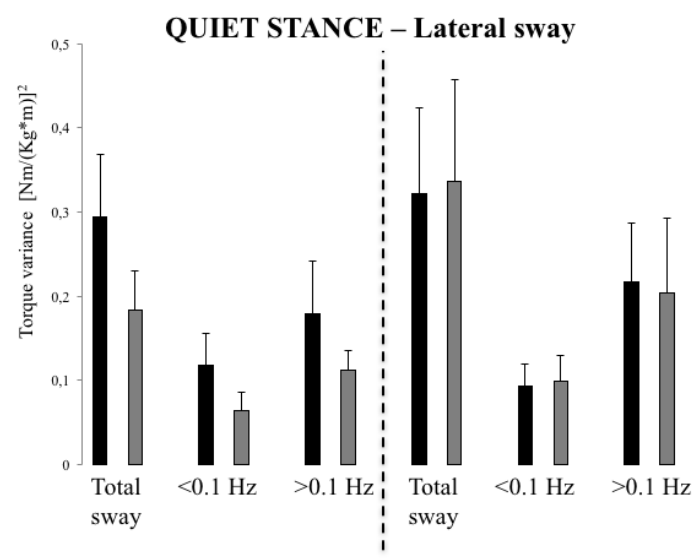

EYES CLOSED

EYES OPEN

Fig 2. Quiet stance posturography with and without balancing a book on the head. Presented values are the mean and standard error of mean (SEM). black bars $=$ no book, grey bars $=$ balancing a book on the head
Table 1. GLM-ANOVA statistics of quiet stance data.

\begin{tabular}{|c|c|c|c|c|c|}
\hline \multicolumn{3}{|l|}{ Quiet stance } & \multirow{2}{*}{$\begin{array}{l}\text { Book } \\
0.472\end{array}$} & \multirow{2}{*}{$\begin{array}{l}\text { Vision } \\
0.341\end{array}$} & \multirow{2}{*}{$\begin{array}{c}\begin{array}{c}\text { Book } \\
\text { Vision }\end{array} \\
0.596\end{array}$} \\
\hline \multirow{6}{*}{$\begin{array}{l}\text { Anteroposterior } \\
\text { sway }\end{array}$} & \multirow[b]{2}{*}{ Total } & p-value & & & \\
\hline & & $\mathrm{F}$ & 0.6 & 1.0 & 0.2 \\
\hline & \multirow[b]{2}{*}{$<0.1 \mathrm{~Hz}$} & p-value & 0.360 & 0.457 & 0.908 \\
\hline & & $\mathrm{F}$ & 0.9 & 0.6 & 0.0 \\
\hline & \multirow[b]{2}{*}{$>0.1 \mathrm{~Hz}$} & $\mathrm{p}$-value & 0.657 & 0.015 & 0.278 \\
\hline & & $\mathrm{F}$ & 0.2 & 8.7 & 0.278 \\
\hline \multirow{6}{*}{ Lateral sway } & \multirow[b]{2}{*}{ Total } & $\mathrm{p}$-value & 0.105 & 0.777 & 0.491 \\
\hline & & $\mathrm{F}$ & 3.2 & 0.1 & 0.5 \\
\hline & \multirow[b]{2}{*}{$<0.1 \mathrm{~Hz}$} & p-value & 0.058 & 0.805 & 0.188 \\
\hline & & $\mathrm{F}$ & 4.6 & 0.1 & 2.0 \\
\hline & \multirow[b]{2}{*}{$>0.1 \mathrm{~Hz}$} & p-value & 0.143 & 0.712 & 0.739 \\
\hline & & $\mathrm{F}$ & 2.5 & 0.1 & 0.1 \\
\hline
\end{tabular}

during EO in total anteroposterior sway $(\mathrm{p}=0.032)$ and total lateral sway $(\mathrm{p}=0.020)$, with the majority of improvement in sway $<0.1 \mathrm{~Hz}$ in both anteroposterior $(\mathrm{p}=0.009)$ and lateral plane $\mathrm{p}=0.045)$.

Figure 4A-B depicts the area on the platform, upon which the balancing forces, from one subject, were actuated during eyes open condition and balancing a book (B) or not (A). The area over which the subject exerted correctional forces decreased considerably in the anteroposterior plane when standing with a book on the head.

\section{Discussion}

Postural parameters were affected by balancing a book on the head. During postural perturbations (vibratory calf stimulation) the stability improved significantly when the subjects had a book on their heads, with less forces actuated on the platform i.e., less energy was spent while standing. The graph in figure 2 also suggest that balancing a book on the head also affect postural control in quiet stance (without perturbation) with and without visual cues, though the difference was not significant. The improvement might have been due to that the book's weight provided an external gravity reference, or to that the balancing act diverted attention from maintaining postural control towards a focus on keeping the book on the head (i.e., balancing a book constituted a minor cognitive task), or both.

As an external reference, it is possible that the book conveyed information about head movements since changes of the books pressure on the head would signal changes of the gravitation vector of the head and thus help the postural control system to attenuate body sway during a perturbation, as a kind of haptic control. Very much in the same way as the somatosensory system can provide a spatial reference frame for the postural control system by simply touching an object during postural perturbations, and thus relating to allocentric reference frames [25]. Both the task of maintaining postural control and balancing a book would have the aim to stabilize the head in space through a top-down representation [26], and possibly also explain why postural sway was predominantly affected by the book-balancing act during test conditions with eyes open.

Cognitive influence on postural control has been investigated during different conditions (dual-task, backwards counting, digital tasks etc.) with various results. The theory is that a postural and a cognitive task effectuated at the same time compete for a finite cortical capacity, and that the task perceived as most important is given priority [27]. We did not measure any performance of the book-balancing act other than recording that none dropped their book, so in this sense the present study does not evaluate dual tasks. Generally it appears that 
Table 2. GLM ANOVA statistics during the 4 periods of vibratory perturbation.

\begin{tabular}{|c|c|c|c|c|c|c|c|c|c|}
\hline \multicolumn{3}{|c|}{$\begin{array}{l}\text { Vibratory } \\
\text { Perturbation }\end{array}$} & Book & Vision & Period & $\begin{array}{c}\text { Book } \\
\text { Vision }\end{array}$ & $\begin{array}{c}\text { Book } \\
\text { period }\end{array}$ & $\begin{array}{l}\text { Vision } \\
\text { Period }\end{array}$ & $\begin{array}{l}\text { Book Vision } \\
\text { Period }\end{array}$ \\
\hline \multirow{6}{*}{$\begin{array}{l}\text { Antero } \\
\text { Posterior } \\
\text { Sway }\end{array}$} & \multirow[t]{2}{*}{ Total } & $\mathrm{p}$-value & 0.179 & $<0.001$ & $<0.001$ & 0.114 & 0.363 & 0.309 & 0.180 \\
\hline & & $\mathrm{F}$ & 2.1 & 66.7 & 53.2 & 2.9 & 0.9 & 1.1 & 2.1 \\
\hline & \multirow[t]{2}{*}{$<0.1 \mathrm{~Hz}$} & $\mathrm{p}$-value & 0.263 & 0.008 & $<0.001$ & 0.002 & 0.371 & 0.165 & 0.549 \\
\hline & & F & 1.4 & 10.3 & 66.0 & 16.0 & 0.9 & 2.2 & 0.4 \\
\hline & \multirow[t]{2}{*}{$>0.1 \mathrm{~Hz}$} & p-value & 0.287 & $<0.001$ & $<0.001$ & 0.606 & 0.465 & 0.053 & 0.342 \\
\hline & & F & 1.3 & 90.7 & 29.2 & 0.3 & 0.6 & 4.7 & 1.0 \\
\hline \multirow{6}{*}{$\begin{array}{l}\text { Lateral } \\
\text { Sway }\end{array}$} & \multirow[t]{2}{*}{ Total } & $\mathrm{p}$-value & 0.082 & 0.001 & 0.121 & 0.969 & 0.101 & 0.197 & 0.622 \\
\hline & & F & 3.7 & 20.3 & 2.8 & 0.0 & 3.2 & 1.9 & 0.3 \\
\hline & \multirow[t]{2}{*}{$<0.1 \mathrm{~Hz}$} & $\mathrm{p}$-value & 0.108 & 0.178 & 0.023 & 0.430 & 0.434 & 0.244 & 0.117 \\
\hline & & F & 3.1 & 2.1 & 6.9 & 0.7 & 0.7 & 1.5 & 2.9 \\
\hline & \multirow[t]{2}{*}{$>0.1 \mathrm{~Hz}$} & $\mathrm{p}$-value & 0.225 & $<0.001$ & 0.371 & 0.434 & 0.154 & 0.064 & 0.239 \\
\hline & & F & 1,7 & 40.5 & 0.9 & 0.7 & 2.3 & 4.2 & 1.6 \\
\hline
\end{tabular}

A

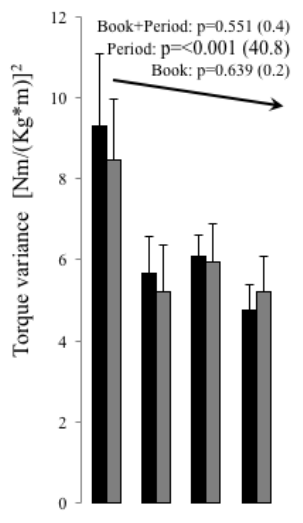

Period 1-4

Total sway

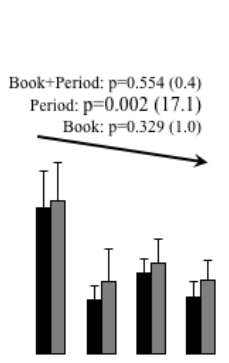

Period 1-4

$<0.1 \mathrm{~Hz}$

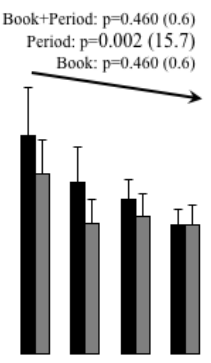

Period 1-4

$>0.1 \mathrm{~Hz}$

Anterioposterior sway, Eyes Closed

C

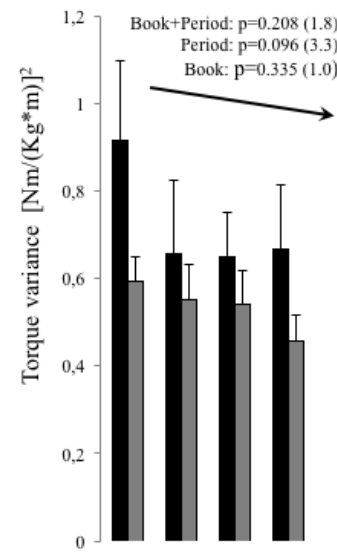

Period 1-4

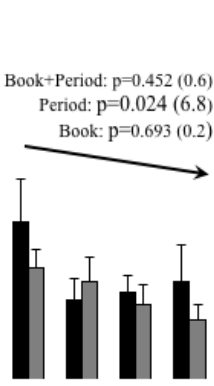

Period 1-4

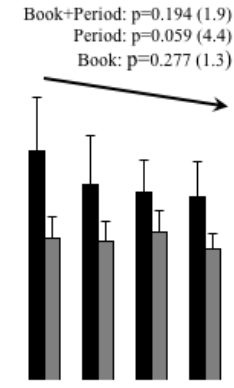

Period 1-4

$>0.1 \mathrm{~Hz}$

Lateral sway, Eyes Closed

Fig 3. Posturography during the 4 periods of vibratory perturbation.

The post-hoc GLM ANOVA statistics are given in the figure, with the F-value within brackets. Presented values are the mean and standard error of mean (SEM).

black bars $=$ no book, grey bars $=$ balancing a book on the head

B

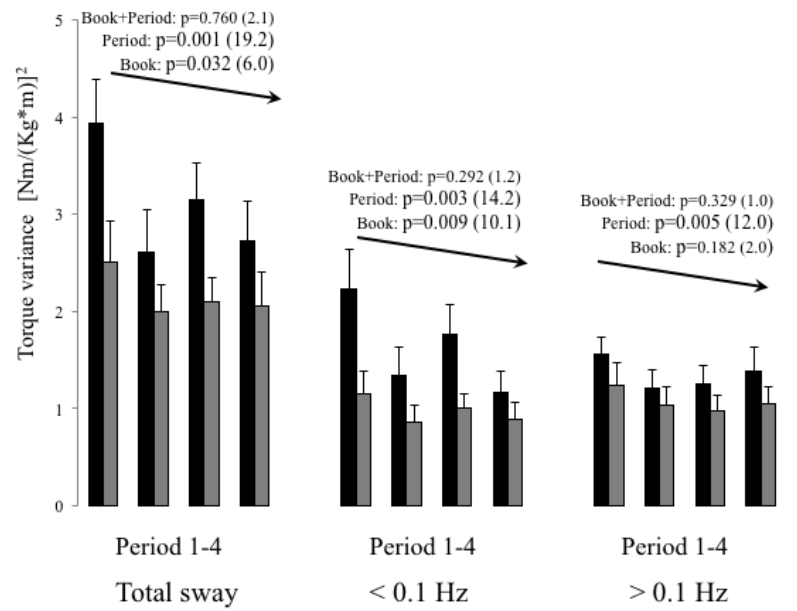

Anterioposterior sway, Eyes Open

D

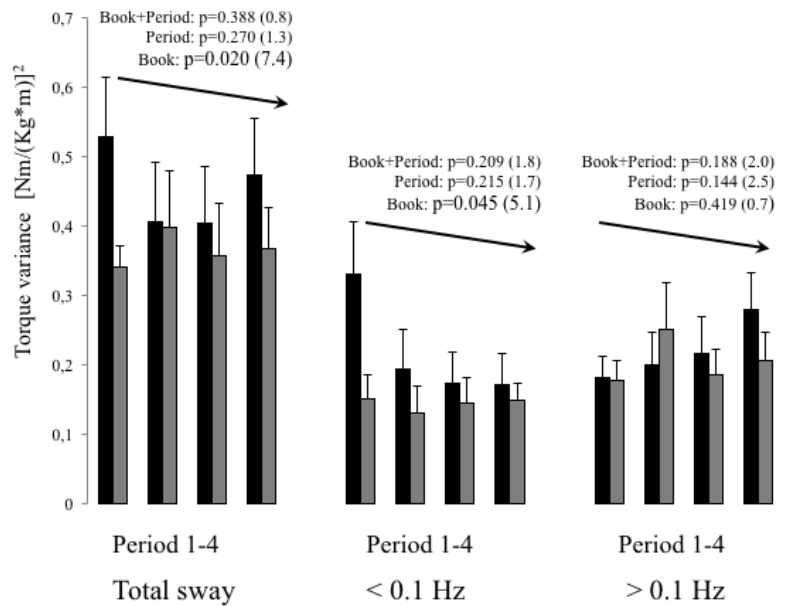

Lateral sway, Eyes Open 
A

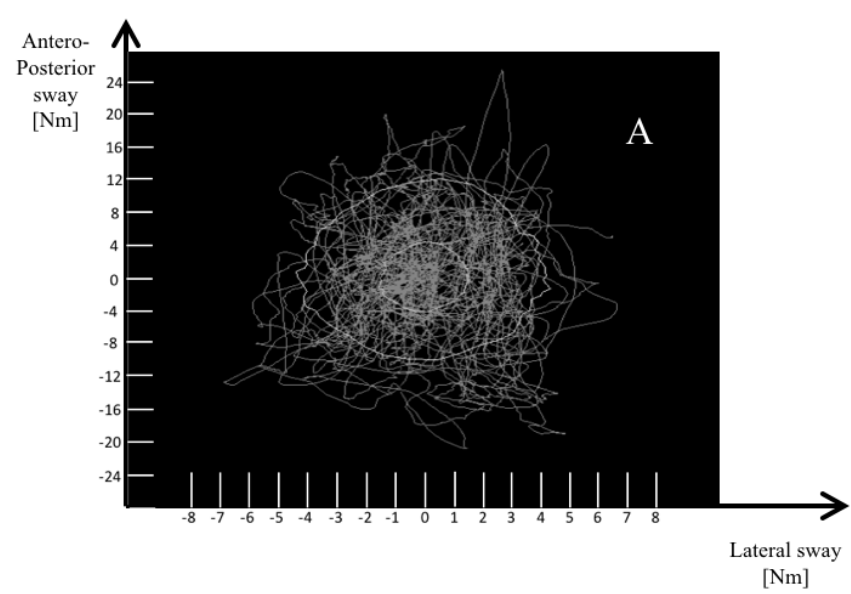

B

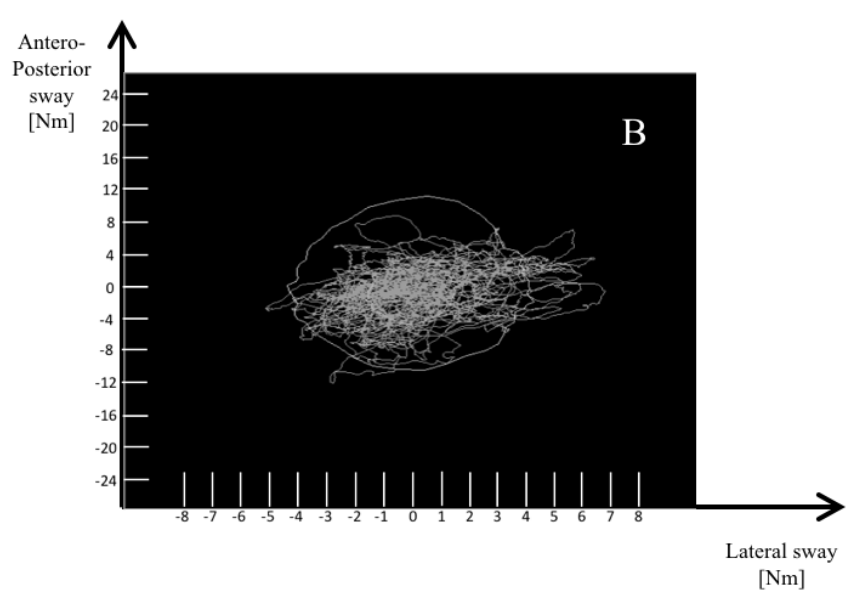

Fig 4. Platform recording.

The area on the platform over which correctional forces were actuated during the vibratory perturbation in one subject during eyes open test. $\mathrm{A}=$ no book, $\mathrm{B}=$ balancing a book on the head

cognitive tasks affect postural control negatively if it already is impaired $[28,29]_{2}$ or if the cognitive capacity itself is reduced [22]. The impact of a cognitive task seems also to be relative to the difficulty of the task, where postural sway decreases with increasing cognitive demand [30,31]. Taken together if balancing of a book constitutes a cognitive task or a task given priority, the results would make sense, i.e. that postural sway decreased during an easy task (EO) but was unaffected during a more difficult postural task (EC). The consequences from failure of the book task, i.e. dropping the book, were not severe and as such the task would not be given priority during EC and thus may not have constituted an external focus (compared to the vibratory perturbation) during EC condition. The lack of "book-effect" during EC could also suggest more dependence on vestibular and somatosensory feedback cues than on book-gravity cues. For rehabilitation purposes the EO condition is similar to most conditions involved in daily activities.

The balancing of a book on the head primarily improved postural control when visual cues were available. The improvement consisted of a change into a more stable position and through a reduction of the smooth corrective body movements in overall stance. The area over which the CoP was exerted during perturbations changed when balancing a book. The anteroposterior swaypath became reduced and since there thus is greater distance to postural limits, where the CoP exceeds the base of support, the reduction of swaypath could entail a greater capacity for postural adjustments. There was no change of the reflexive $(>0.1 \mathrm{~Hz})$ corrective body movements, suggesting that the book-balancing act did not affect fast corrective adjustments involved in feed-back control.

Postural control improved during the perturbations over time, which supports earlier results [32], and the improvement was most pronounced during eyes closed and in anteroposterior direction. Adaptation to postural perturbations is mostly seen in the reflexive, feed-back dependent quick movements $>0.1 \mathrm{~Hz}$ [32], and this capacity for adaptation was not augmented by balancing a book in any condition, nor frequency. It could be that any effects from the book were attenuated, since the adaptation to postural perturbations without a book already was great [32].

\section{Conclusion}

The study demonstrates that balancing a book on the head affects postural sway and reduces the energy spent while standing. The concept constitutes an easy and accessible method, which could be attractive from a postural rehabilitation perspective, though the effect on patients with poor postural control with imbalance and/or dizziness remains to be studied.

\section{References}

1. Johansson R, Magnusson M, Akesson M (1988) Identification of human postural dynamics. IEEE Trans Biomed Eng 35: 858-869. [Crossref]

2. Peterka RJ (2002) Sensorimotor integration in human postural control. J Neurophysiol 88: 1097-1118. [Crossref]

3. Tjernström F, Fransson PA, Patel M, Magnusson M (2010) Postural control and adaptation are influenced by preceding postural challenges. Exp Brain Res 202: 613621. [Crossref]

4. Herdman SJ, Clendaniel RA, Mattox DE, Holliday MJ, Niparko JK (1995) Vestibular adaptation exercises and recovery: acute stage after acoustic neuroma resection. Otolaryngol Head Neck Surg. 113: 77-87. [Crossref]

5. Martin JT, Wolf A, Moore JL, Rolenz E, DiNinno A, Reneker JC (2013) The effectiveness of physical therapist-administered group-based exercise on fall prevention: a systematic review of randomized controlled trials. J Geriatr Phys Ther. 36: 182-193. [Crossref]

6. Saywell N, Taylor D (2008) The role of the cerebellum in procedural learning--are there implications for physiotherapists' clinical practice?. Physiother Theory Pract. 24: 321-328. [Crossref]

7. Herdman SJ (1998) Role of vestibular adaptation in vestibular rehabilitation Otolaryngol Head Neck Surg 119: 49-54. [Crossref]

8. Basta D, Rossi-Izquierdo M, Soto-Varela A, Greters ME, Bittar RS. et al. (2011) Efficacy of a vibrotactile neurofeedback training in stance and gait conditions for the treatment of balance deficits: a double-blind, placebo-controlled multicenter study. Otol Neurotol, 32: 1492-1499. [Crossref]

9. Barcala L, Grecco LA, Colella F, Lucareli PR, Salgado AS (2013) Visual biofeedback balance training using wii fit after stroke: a randomized controlled trial. $J$ Phys Ther Sci, 25: 1027-1032. [Crossref]

10. Kingma H, Gauchard GC, de Waele C, van Nechel C, Bisdorff A, et al. (2011) Stocktaking on the development of posturography for clinical use. J Vestib Res 21 : 117-125. [Crossref]

11. Fransson P, Johansson R, Hafström A, Magnusson M (2000) Methods for evaluation of postural control adaptation. Gait Posture 12: 14-24. [Crossref]

12. Johansson R, Magnusson M, Fransson PA (1995) Galvanic vestibular stimulation for analysis of postural adaptation and stability. IEEE Trans Biomed Eng 42: 282-292. [Crossref]

13. Matthews $P$ (1986) What are the afferents of origin of the human stretch reflex, and is it a purely spinal reaction? In: Freund, HJ. Büttner, U. Cohen, B. Noth, J eds. Progress 
in Brain Research. Amsterdam: Elsevier Science Publishers B.V. (Biomechanical Division) 64: 55-66.

14. Goodwin GM, McCloskey DI, Matthews PB (1972) Proprioceptive illusion induced by muscle vibration-Contribution by muscle spindles to perception?. Science. 175: 13821384. [Crossref]

15. Johansson R (1993) System Modeling and Identification. NJ: Prentice Hall Englewood Cliffs.

16. Patel M, Gomez S, Berg S, Almbladh P, Lindblad J, et al. (2008) Effects of 24-h and 36-h sleep deprivation on human postural control and adaptation. Exp Brain Res 185: 165-173. [Crossref]

17. Johansson R, Fransson PA, Magnusson M (2009) Optimal coordination and control of posture and movements. J Physiol Paris 103: 159-177. [Crossref]

18. Riccio GE, Stoffregen TA (1988) Affordance as contrstraints on the control of stance. Human Movement Science 7: 265-300.

19. Fransson PA, Hjerpe M, Johansson R (2007) Adaptation of multi-segmented body movements during vibratory proprioceptive and galvanic vestibular stimulation. $J$ Vestib Res, 17: 47-62. [Crossref]

20. Fransson PA (2009) Adaptation of Human Postural Control: Learning, sensorimotor and analysis aspects. Saarbrücken VDM Verlag.

21. Proakis JG (1989) Introduction to Digital Signal Processing. New York: Macmillan.

22. Petersen H, Magnusson M, Fransson PA, Johansson R (1994) Vestibular disturbance at frequencies above $1 \mathrm{~Hz}$ affects human postural control. Acta Otolaryngol 114: 225230. [Crossref]

23. Tjernström F, Fransson PA, Hafström A, Magnusson M (2002) Adaptation of postural control to perturbations--a process that initiates long-term motor memory. Gait Posture 15: 75-82. [Crossref]

24. Altman D (1991) Practical statistics for medical research. New York: Chapman \& Hall NY.

25. Jeka J, Oie K, Schöner G, Dijkstra T, Henson E (1998) Position and velocity coupling of postural sway to somatosensory drive. J Neurophysiol 79: 1661-1674. [Crossref]

26. Nicholas SC, Doxey-Gasway DD, Paloski WH (1998) A link-segment model of upright human posture for analysis of head-trunk coordination. J Vestib Res 8: 187-200. [Crossref]

27. Maki BE, McIlroy WE (2007) Cognitive demands and cortical control of human balance-recovery reactions. J Neural Transm (Vienna) 114: 1279-1296. [Crossref]

28. Brauer SG, Woollacott M, Shumway-Cook A (2001) The interacting effects of cognitive demand and recovery of postural stability in balance-impaired elderly persons. $J$ Gerontol A Biol Sci Med Sci 56: M489-496. [Crossref]

29. Marchese R, Bove M, Abbruzzese G (2003) Effect of cognitive and motor tasks on postural stability in Parkinson's disease: a posturographic study. Mov Disord 18: 652658. [Crossref]

30. Andersson G, Hagman J, Talianzadeh R, Svedberg A, Larsen HC (2002) Effect of cognitive load on postural control. Brain Res Bull 58: 135-139. [Crossref]

31. Riley MA, Baker AA, Schmit JM (2003) Inverse relation between postural variability and difficulty of a concurrent short-term memory task. Brain Res Bull, 62: 191-195. [Crossref]

32. Tjernström F, Fransson PA, Hafström A, Magnusson M (2002) Adaptation of postural control to perturbations--a process that initiates long-term motor memory. Gait Posture 15: 75-82. [Crossref]

Copyright: (C2016 Malmström EM. This is an open-access article distributed under the terms of the Creative Commons Attribution License, which permits unrestricted use, distribution, and reproduction in any medium, provided the original author and source are credited. 